\title{
Cumulative incidence and mortality of infective endocarditis in Siriraj hospital- Thailand: a 10-year retrospective study
}

\author{
Taksaon Angsutararux and Nasikarn Angkasekwinai ${ }^{*}$ [D
}

\begin{abstract}
Background: To investigate the cumulative incidence of and factors associated with mortality among patients with infective endocarditis (IE) at Thailand's largest national tertiary referral center.

Methods: Medical charts of adult patients diagnosed with IE by Duke criteria at Siriraj Hospital during January 2005 to May 2015 were retrospectively reviewed.

Results: Of 380 patients, 66.3\% had definite IE, and $81.3 \%$ had native valve IE (NVE). Cumulative IE incidence was 5.67/1000 admissions. The most common pathogens were viridans group streptococci (VGS) (39.7\%), methicillinsensitive Staphylococcus aureus (MSSA) (13.1\%), and beta-hemolytic streptococci (11.5\%) in NVE; and, MSSA (20.3\%), VGS (20.3\%), and Enterococcus spp. (16.9\%) in prosthetic valve (PVE) or device-related IE (DRIE). Overall in-hospital mortality was $18.4 \%$. Mortality was significantly higher in PVE/DRIE than in NVE (26.8\% vs. $16.5 \%, p=0.047)$. Endstage renal disease (ESRD) (aOR: 9.43, 95\% Cl: 2.36-37.70), diabetes mellitus (DM) (aOR: 2.81, 95\% Cl: 1.06-7.49), neurological complication (aOR: 14.16, 95\% Cl: 5.11-39.22), congestive heart failure (aOR: 4.32, 95\% Cl: 1.91-9.75), hospital-acquired infection (aOR: 3.78, 95\% Cl: 1.66-8.57), renal complication (aOR: 3.12, 95\%Cl: 1.32-7.37), and other complication during admission (aOR: 3.28, 95\% Cl: 1.41-7.61) were independently associated with mortality.

Conclusions: The incidence of $\mathrm{IE}$, and the mortality rate among those diagnosed with IE are both increasing in Thailand - particularly among those with PVE or DRIE. End-stage renal disease, diabetes mellitus, and development of IE-related complications during admission were found to be independent predictors of mortality.
\end{abstract}

Keywords: Infective endocarditis, IE, Native valve IE, Prosthetic valve IE

\section{Background}

Infective endocarditis (IE) poses a great therapeutic challenge due to difficulties in diagnosis and the high risk of morbidity. Since a decrease in the late 1960's, the inhospital mortality rate has remained relatively stable at approximately $20 \%$ [1]. Within the last decade, the epidemiology of IE has changed significantly worldwide. Recent study found an increase in IE among elderly population with comorbidities, and among patients that use invasive medical devices, such as intracardiac device, prosthetic heart valve, or hemodialysis catheter. These factors were also reported to be at least partially

\footnotetext{
* Correspondence: nasikarn@gmail.com

Division of Infectious Diseases and Tropical Medicine, Department of

Medicine, Faculty of Medicine Siriraj Hospital, Mahidol University, 2 Wanglang Road, Bangkoknoi, Bangkok 10700, Thailand
}

responsible for changing the patterns of the causative pathogens [2, 3]. Several studies reported an increased proportion of staphylococcal IE, and a decreased proportion of IE caused by viridans group streptococci (VGS) [4]. However, most studies in IE were conducted in North America or Europe, and data specific to the epidemiology of IE in Southeast Asia is relatively scarce. Two previous studies were conducted in Northeastern Thailand $[5,6]$. The epidemiology of IE may vary among continents, geographic regions, and by type of hospital. Improved understanding of the epidemiology of IE, including the pathogens that cause IE, will help to guide the selection of empirical antibiotic therapy.

The aim of this study was to determine the cumulative incidence, clinical characteristics, microbial etiology, mortality, and factors associated with in-hospital mortality

(c) The Author(s). 2019 Open Access This article is distributed under the terms of the Creative Commons Attribution 4.0 International License (http://creativecommons.org/licenses/by/4.0/), which permits unrestricted use, distribution, and reproduction in any medium, provided you give appropriate credit to the original author(s) and the source, provide a link to the Creative Commons license, and indicate if changes were made. The Creative Commons Public Domain Dedication waiver (http://creativecommons.org/publicdomain/zero/1.0/) applies to the data made available in this article, unless otherwise stated. 
among patients with infective endocarditis admitted to the largest tertiary medical center in Thailand.

\section{Methods}

This retrospective cohort study was conducted at the Division of Infectious Diseases and Tropical Medicine, Department of Medicine, Faculty of Medicine Siriraj Hospital, Mahidol University, Bangkok, Thailand. Siriraj Hospital is the largest tertiary and quaternary-care medical center in Thailand, with a capacity of more than 2000 beds and more than one million outpatient visits per year. All adult patients aged over 15 years who were admitted during 1 January 2005 to 31 May 2015 that were diagnosed with infective endocarditis (IE) according to modified Duke criteria were included. Diagnosis of IE was identified from the computer record using ICD-10 I33.0 as the diagnostic code. Patient data relating to demographics, clinical characteristics, microbiological findings, occurrence of complication, echocardiographic findings, treatment, and outcome were collected, recorded, and analyzed.

The presumed mode of acquisition of IE was categorized as community-acquired IE (CA-IE) or healthcareassociated IE (HA-IE). HA-IE was further subdivided into nosocomial or non-nosocomial. Nosocomial IE (NIE) was defined as IE that developed in a patient hospitalized $>48 \mathrm{~h}$ prior to the onset of signs/symptoms consistent with IE. Non-nosocomial IE (NNIE) was defined as signs and/or symptoms of IE starting $<48 \mathrm{~h}$ after admission in a patient with healthcare contact consisting of home-based nursing or intravenous therapy, hemodialysis or intravenous chemotherapy $<30$ days, hospitalized in an acute care facility $<90$ days before the onset of IE, or resident in a nursing home/long-term care facility [7]. All cases not fulfilling the criteria for healthcareassociated infection were defined as community-acquired IE. The type of heart involvement was classified as native valve IE (NVE), prosthetic valve IE (PVE), or devicerelated IE (DRIE). DRIE was defined as IE developing on pacemaker or defibrillator wires with or without associated valve involvement. Abnormal echocardiogram was defined as vegetation, abscess, or new dehiscence of a prosthetic valve from transthoracic echocardiography (TTE) or transesophageal echocardiography (TEE) [7].

Inappropriate antibiotic was defined as a prescription for an antibiotic to which the organism was non-susceptible in vitro according to the identified organism from hemoculture or tissue culture, as well as antibiotic other than guideline recommendation [7] in culture-negative IE. The primary outcome was in-hospital mortality.

\section{Sample size calculation}

Previous study reported the incidence of in-hospital mortality rate among patients with IE to be $14 \%$ [8]. The sample size was a priori calculated to estimate a single proportion with precision of $3.5 \%$ and a confidence interval of 95\% using n Query Advisor program (Statistical Solutions, Ltd., Cork, Ireland). Therefore, the sample size needed to determine incidence of in-hospital mortality was 378 participants.

We performed post-hoc power analysis using $G^{*}$ Power 3.1.9.2 after a study has been completed to investigate a type II error in the study. A logistic regression of mortality on neurological complication at diagnosis as one covariate and adjusted for the other covariates in the model with a sample size of 308 participants (of which $17.6 \%$ were in the neurological complication group and $82.4 \%$ were in the non-neurological complication group) achieves $60 \%$ power for a two-sided test at 0.05 significance level to detect a change in probability of mortality from the baseline value of 0.152 to 0.286 . This change corresponds to an odds ratio of 2.24. An adjustment was made since a multiple logistic regression of the independent variable with the largest $p$-value (neurological at diagnosis) on the other independent variables in the logistic regression model obtained an R-Squared of 0.06 .

\section{Statistical analysis}

Data analysis was performed using SPSS Statistics software version 23 for Windows (SPSS, Inc., Chicago, IL, USA). Descriptive statistics were used to summarize patient demographic and baseline clinical characteristics. Categorical variables, including mortality rate, were reported as frequency and percentage. The cumulative incidence of IE referred to the proportion of IE among patients admitted to the hospital and was reported as number of patients with IE per 1000 medical admissions. Continuous data are expressed as mean plus/minus standard deviation (SD) or median and range, as appropriate. Chi-square test or Fisher's exact test was used to analyze for association between categorical clinical variables. Independent samples $t$-test or Mann-Whitney U test was used to analyze for association between a continuous variable and a categorical variable with two categories. Variables with a $p$-value $<0.05$ were further analyzed for independent association with mortality using multiple logistic regression. Those results are reported as adjusted odds ratio (aOR) and 95\% confidence interval $(95 \% \mathrm{CI})$. A $p$-value of $<0.05$ was considered statistically significant for all tests.

\section{Results}

A total of 380 patients were enrolled in this study for a cumulative incidence of IE of 5.67 per 1000 admissions. Of those, 318 patients $(83.7 \%)$ were diagnosed IE at the time of admission and were admitted to a medical ward, and 62 patients $(16.3 \%)$ were transferred or referred for surgery and admitted to the cardiovascular and thoracic 
(CVT) surgery ward. The clinical characteristics of the 380 included patients are shown in Table 1 . The median age of all patients was 53 years (range: 15-91), and most patients (63.4\%) were male. Half of all patients had at least one comorbid disease. Among the 380 patients, $252(66.3 \%)$ had definite IE, and $128(33.7 \%)$ were

Table 1 Demographic and clinical characteristics of 380 patients according to type of heart involvement

\begin{tabular}{|c|c|c|c|c|}
\hline Characteristics & All IE $(n=380) \mathrm{n}(\%)$ & NVE $(n=309) \mathrm{n}(\%)$ & PVE or DRIE $(n=71) \mathrm{n}(\%)$ & $p$-value \\
\hline Age (years), median (range) & $53(15-91)$ & $53(15-91)$ & $59(16-85)$ & 0.081 \\
\hline Male gender & $241(63.4)$ & $197(63.8)$ & $44(62.0)$ & 0.779 \\
\hline Comorbid disease & $187(49.2)$ & $142(46.0)$ & $45(63.4)$ & 0.008 \\
\hline Hypertension & $91(23.9)$ & $66(21.4)$ & $25(35.2)$ & 0.014 \\
\hline Diabetes & $57(15.0)$ & $42(13.6)$ & $15(21.1)$ & 0.109 \\
\hline Hyperlipidemia & $38(10.0)$ & $27(8.7)$ & $11(15.5)$ & 0.087 \\
\hline End-stage renal disease & $21(5.5)$ & $17(5.5)$ & $4(5.6)$ & 0.965 \\
\hline Cancer & $21(5.5)$ & $17(5.5)$ & $4(5.6)$ & 0.965 \\
\hline Coronary artery disease & $16(4.2)$ & $7(2.3)$ & $9(12.7)$ & $<0.001$ \\
\hline \multicolumn{5}{|l|}{ IE characteristic } \\
\hline Definite IE & $252(66.3)$ & $215(69.6)$ & $37(52.1)$ & \multirow[t]{2}{*}{0.005} \\
\hline Possible IE & $128(33.7)$ & $94(30.4)$ & $34(47.9)$ & \\
\hline \multicolumn{5}{|l|}{ Mode of acquisition of IE } \\
\hline Community-acquired & $321(84.5)$ & $280(90.6)$ & $41(57.7)$ & 1.00 \\
\hline Nosocomial associated & $45(11.8)$ & $20(6.5)$ & $25(35.2)$ & $<0.001$ \\
\hline Non-nosocomial associated & $14(3.7)$ & $9(2.9)$ & $5(7.0)$ & 0.015 \\
\hline Abnormal echocardiogram ${ }^{a}$ & $326 / 372(87.6)$ & 278/305 (91.1) & 48/67 (71.6) & $<0.001$ \\
\hline \multicolumn{5}{|l|}{ Affected valve } \\
\hline Mitral valve & $166(43.7)$ & $152(49.2)$ & $14(19.7)$ & $<0.001$ \\
\hline Aortic valve & $105(27.6)$ & $85(27.5)$ & $20(28.2)$ & 0.911 \\
\hline Multiple valve & $19(5.0)$ & $16(5.2)$ & $3(4.2)$ & 1.000 \\
\hline Tricuspid valve & $9(2.4)$ & $7(2.3)$ & $2(2.8)$ & 0.677 \\
\hline Other & $26(6.8)$ & $17(5.5)$ & $9(12.7)$ & 0.039 \\
\hline Vegetation observed ${ }^{\mathrm{b}}$ & 239/331 (72.2) & 209/269 (77.7) & 30/62 (48.4) & $<0.001$ \\
\hline Complication at diagnosis & $229(60.3)$ & $186(60.2)$ & $43(60.6)$ & 0.954 \\
\hline Congestive heart failure & $145(38.2)$ & $111(35.9)$ & $34(47.9)$ & 0.61 \\
\hline Arrhythmia & $8(2.1)$ & $3(1.0)$ & $5(7.0)$ & 0.001 \\
\hline Neurological & $67(17.6)$ & $61(19.7)$ & $6(8.5)$ & 0.024 \\
\hline Other & $37(11.6)$ & $32(12.5)$ & $5(7.9)$ & 0.307 \\
\hline Positive hemoculture ${ }^{c}$ & $311(82.1)$ & $252(81.8)$ & $59(83.1)$ & 0.80 \\
\hline \multicolumn{5}{|l|}{ Causative pathogen } \\
\hline Streptococcus spp. & $189(60.8)$ & $169(67.1)$ & $20(33.9)$ & $<0.001$ \\
\hline Staphylococcus spp. & $69(22.2)$ & $48(19.0)$ & $21(35.6)$ & 0.006 \\
\hline Enterococcus spp. & $31(10.0)$ & $21(8.3)$ & $10(16.9)$ & 0.047 \\
\hline Gram-negative bacilli & $10(3.2)$ & $7(2.8)$ & $3(5.1)$ & 0.408 \\
\hline HACEK & $6(1.9)$ & $4(1.6)$ & $2(3.4)$ & 0.319 \\
\hline Other Gram-positive bacteria & $5(1.6)$ & $3(1.2)$ & $2(3.4)$ & 0.241 \\
\hline Fungus & $1(0.3)$ & $0(0.0)$ & $1(1.7)$ & 0.190 \\
\hline
\end{tabular}

A $p$-value $<0.05$ indicates statistical significance

${ }^{a}$ Available data 331 cases; ${ }^{b}$ Available data for echocardiography 372 cases

cMissing data 1 cases in native valve group

Native valve 309 cases $(81.3 \%)$ 
classified as possible IE. Three hundred and nine patients $(81.31 \%)$ had native valve endocarditis (NVE), 65 patients $(17.01 \%)$ had prosthetic valve endocarditis (PVE), and 6 patients (1.58\%) had device-related infective endocarditis (DRIE).

The demographic and clinical characteristics of patients according to the type of heart involvement are shown in Table 1. Patients with PVE or DRIE were more likely to have comorbid disease $(p=0.008)$, hypertension $(p=$ $0.014)$, coronary artery disease $(p<0.001)$, nosocomial $(p<0.001)$ acquisition, or non-nosocomial acquisition $(p=0.015)$ than patients with NVE. Echocardiographic data were available in 372 (97.9\%) patients, and vegetation was observed significantly more frequently in NVE $(77.7 \%$ vs. $48.4 \%, p<0.001)$. Mitral valve was the most commonly affected valve in NVE (49.2\%), whereas aortic valve was most frequently affected in PVE or DRIE (28.2\%). Congestive heart failure was the most commonly observed complication among the $60 \%$ of patients that had complication on admission.

Data on the clinical presentations of IE were retrieved from the charts of those admitted to medical wards. The common manifestations were fever (88.9\%), new onset murmur (56.3\%), dyspnea (49.1\%), and weight loss (18.2\%). Vascular phenomena were found in $27.4 \%$ of patients, including major arterial embolism (14.5\%), conjunctival hemorrhage (8.2\%), Janeway lesions (3.8\%), intracranial hemorrhage $(2.8 \%)$, and septic pulmonary infarction $(0.3 \%)$. Immunological phenomena were observed in $16 \%$ of patients, including glomerulonephritis (5.7\%), Osler's nodes (5.0\%), rheumatoid factor positive (4.1\%), and Roth spots (3.5\%). Among the 298 IE patients who had comprehensive fever-related data, 78 patients $(26.2 \%)$ experienced a decrease in body temperature within 4 days.

A pathogen was identified in $82 \%$ of all cases. Overall, Streptococcus spp. or Staphylococcus spp. was found in the vast majority of IE cases, accounting for $60 \%$ and $22 \%$, respectively. The causative pathogens of NVE and PVE or DRIE are shown in Fig. 1. A significant difference was observed in the causative agents causing NVE and PVE or DRIE. VGS (39.7\%), MSSA (13.1\%), and betahemolytic streptococci $(11.5 \%)$ were the most common pathogens among NVE; whereas, MSSA (20.3\%), VGS (20.3\%), Enterococcus spp. (16.9\%), and coagulase-negative staphylococci (CoNS) (13.6\%) were more commonly found in PVE or DRIE. The most common type of betahemolytic streptococci was Streptococcus agalactiae (6.1\%).

Seventy of 380 patients died during their hospital stay for an overall in-hospital mortality rate of $18.4 \%$. The mortality rate in the PVE or DRIE group was markedly higher than in the NVE group (26.8\% [19 out of 71 ] vs. $16.5 \%$ [51 out of 309], respectively; $p=0.047$ ). Univariate analysis for factors associated with mortality is shown in
Table 2. The factors that increased mortality in IE were older age (crude OR: 1.04, 95\% CI: 1.02-1.05); female gender (crude OR: 1.98, 95\% CI: 1.17-3.35); PVE or DRIE group; healthcare-associated IE; presence of comorbidity, including hypertension, diabetes mellitus (DM), hyperlipidemia, or end-stage renal disease (ESRD); infection with non-streptococci; having complication at diagnosis, such as congestive heart failure, arrhythmia, or neurological complications; and, development of complication during admission. Patients who underwent surgical treatment had a lower mortality rate than those receiving only medical treatment $(27.1 \%$ vs. $54.2 \%$; $p<$ 0.001). Patients receiving inappropriate initial antibiotic therapy had a significantly higher in-hospital mortality rate than those who received appropriate empirical antibiotic therapy $(25.7 \%$ vs. $12.7 \%, p=0.007)$. Regarding Gram-negative pathogens, all patients with HACEK IE survived, and only 3 of the 10 patients with Gramnegative non-HACEK IE died.

Table 3 shows multivariate analysis for factors associated with mortality. The identified independent risk factors were ESRD (adjusted odds ratio [aOR]: 9.43, 95\% confidence interval [CI]: 2.36-37.70); DM (aOR: 2.81, 95\% CI: 1.06-7.49); neurological complication on admission (aOR: 14.16, 95\% CI: 5.11-39.22); and, complication during admission, including congestive heart failure (aOR: 4.32, 95\% CI: 1.91-9.75), hospital-acquired infection (aOR: 3.78, 95\% CI: 1.66-8.57), renal complication (aOR: 3.12, 95\% CI: 1.32-7.37), and other complication (e.g., septic shock, ARDS, cardiac tamponade, and myocarditis) (aOR: 3.28, 95\% CI: 1.41-7.61). Higher platelet level (aOR: 0.51, 95\% CI: 0.31-0.84) and surgical intervention (aOR: 0.34, 95\% CI: 0.13-0.88) were found to be protective factors against mortality. We also analyzed the data by excluding 62 patients admitted to the surgical department for elective valve repair or replacement to reduce some bias. Among the 318 patients admitted to the medical department, surgery was indicated and performed in 90 patients, and surgery was indicated but not performed in 45 patients. After performing multivariate analysis with 318 participants, surgery remained a protective factor against mortality with an adjusted OR [aOR] of 0.19 (95\% CI: 0.07-0.58). The following factors remained significantly associated with mortality: ESRD (aOR: 7.14, 95\% CI: 1.42-35.95); DM (aOR: 2.78, 95\% CI: 1.02-7.62); neurological complication on admission (aOR: 2.94, 95\% CI: 1.09-7.88); and, complication during admission, including congestive heart failure (aOR: 7.76, 95\% CI: 3.16-19.10), hospital-acquired infection (aOR: 3.22, 95\% CI: 1.38-7.53), renal complication (aOR: 3.61, 95\% CI: $1.50-8.68$ ), or other complication (aOR: 3.86, 95\% CI: 1.59-9.35). Higher platelet level remained a protective factor against mortality with an aOR of 0.51 (95\% CI: 0.31-0.85). In addition, inappropriate antibiotic 


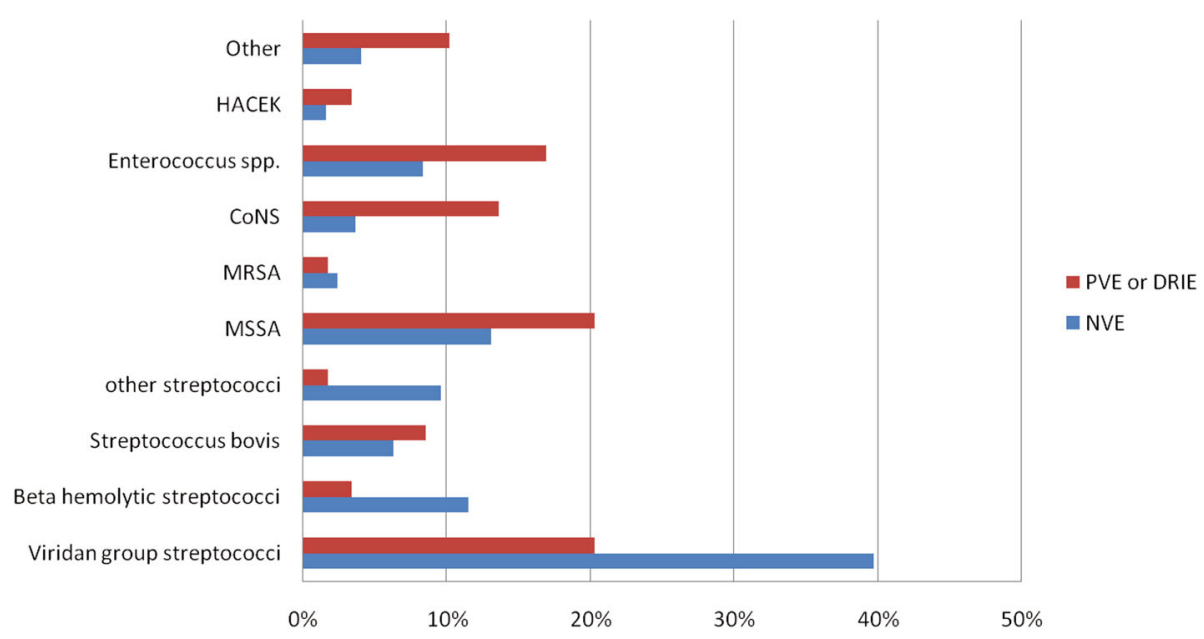

Fig. 1 Causative pathogens compared between native valve endocarditis (NVE) and prosthetic valve endocarditis (PVE) or device related endocarditis (DRIE)

therapy was found to be independently associated with mortality (aOR: 2.87, 95\% CI: 1.03-8.02), whereas IE due to Streptococci was identified as a protective factor against mortality (aOR: 0.17, 95\% CI: 0.04-0.83).

\section{Discussion}

This study revealed a higher cumulative incidence of IE than the rates reported from two previous studies conducted in Thailand. The present study found an incidence of 5.67 per 1000 admissions during the 20052015 study period, which is higher than the previously reported 2.6 cases per 1000 admissions during 19821989 [8], and the previously reported 4 cases per 1000 admissions during 1990-1999 [9]. Moreover, the incidence of IE appears to vary by continent. A systematic review of studies from Europe and the United States during 1970 to 2000 reported an estimated incidence of IE of 1.5 to 6 cases per 100,000 person-years [10]. The incidence of IE in the United States appeared to increase from 11.4 per 100,000 person-years in 1999 to 16.6 per 100,000 person-years in 2006 [11]. Similarly, the incidence increased from 4.1 per 100,000 person-years in 2000-2002 to 4.9 per 100,000 person-years in 20062008 in Northeastern Italy [11]. However, no significant change in the incidence of IE over time was observed in Australia [12] or France [13].

The mean age of patients in our cohort was 53 years, which is lower than the mean age of patients in the International Collaboration on Endocarditis-Prospective Cohort Study (ICE-PCS) (57.9 years). Native valve endocarditis (NVE) was the predominant valve type observed in our study, accounting for $81.3 \%$ of IE cases. However, the percentage of PVE and DRIE was markedly increased compared with previous study in Thailand, from $5 \%$ in 1990-1999 [9] to $18.7 \%$ in this study. A similar trend was observed in a recent systematic review of 142 hospital-based studies, which showed an increasing incidence of IE on prosthetic valve from $8.4 \%$ in the $1960 \mathrm{~s}$ to $22.9 \%$ in the 2000 s [1]. Approximately $40 \%$ of PVE and DRIE in our study were healthcare-associated infection. The patients with PVE or DRIE tended to be older, to have more comorbidities, and to be more likely to be nosocomial or non-nosocomial acquisition than NVE. The increase in the proportion of PVE or DRIE is thought to be partly due to the increasing use of invasive medical devices, which has resulted in a change in the pattern of pathogens that cause IE.

VGS remains the most common pathogen group identified in NVE (40\%), whereas MSSA and VGS were found with equal frequency (20\%) in PVE or DRIE patients. In contrast to our findings, previous study reported a decline in the frequency of IE caused by VGS over time from $27.4 \%$ in the 1960 s to $17.6 \%$ in the 2000 s on all continents including Asia [1], and an increased proportion of IE due to $S$. aureus from less than $10 \%$ to more than 25\% [2, 14]. However, epidemiological studies of IE in Asian populations are scarce. A previous study in $180 \mathrm{IE}$ cases conducted at a large tertiary-care teaching hospital in Japan during 2000 to 2014 [15] found $S$. aureus to be the leading cause of IE (27\%), followed by VGS (22\%). Of note, the mean age of patients in that study was 69 years, which is far higher than the mean age of patients in other studies. A recent systematic review [4] that included 105 studies from 36 countries (a total of 33,214 IE cases) reported a trend toward more $S$. aureus etiology causing IE, especially among intravenous drug use patients. However, VGS remains the most common pathogen in the sub-group population from Asia. Previous studies conducted at a university hospital in Northeastern Thailand also found VGS to be the 
Table 2 Factors associated with overall mortality

\begin{tabular}{|c|c|c|c|c|}
\hline Factors & Total $(n=380) n(\%)$ & Alive $(n=310) \mathrm{n}(\%)$ & Dead $(n=70) \mathrm{n}(\%)$ & $p$-value \\
\hline Age (years), mean $\pm S D$ & & $49.5 \pm 17.4$ & $59.9 \pm 17.8$ & $<0.001$ \\
\hline Male gender & $241(63.4)$ & $206(66.5)$ & $35(50.0)$ & 0.011 \\
\hline \multicolumn{5}{|l|}{ Type of heart involvement } \\
\hline Native valve & $309(81.3)$ & $258(83.2)$ & $51(72.9)$ & \multirow[t]{2}{*}{0.047} \\
\hline $\mathrm{PVE}+\mathrm{DRIE}$ & $71(18.7)$ & $52(16.8)$ & $19(27.1)$ & \\
\hline \multicolumn{5}{|l|}{ Mode of acquisition of IE } \\
\hline Community-acquired & $321(84.5)$ & $276(89.0)$ & $45(64.3)$ & \\
\hline Healthcare-associated & $59(15.5)$ & $34(11.0)$ & $25(35.7)$ & $<0.001$ \\
\hline Comorbid disease & $187(49.2)$ & $137(44.2)$ & $50(71.4)$ & $<0.001$ \\
\hline Hypertension & $91(23.9)$ & $61(19.7)$ & $30(42.9)$ & $<0.001$ \\
\hline Diabetes Mellitus & $57(15.0)$ & $34(11)$ & $23(32.9)$ & $<0.001$ \\
\hline Hyperlipidemia & $38(10.0)$ & $26(8.4)$ & $12(17.1)$ & 0.031 \\
\hline End-stage renal disease & $21(5.5)$ & $11(3.5)$ & $10(14.3)$ & 0.001 \\
\hline Cancer & $21(5.5)$ & $19(6.1)$ & $2(2.9)$ & 0.29 \\
\hline Coronary artery disease & $16(4.2)$ & $11(3.5)$ & $5(7.1)$ & 0.185 \\
\hline \multicolumn{5}{|l|}{ IE characteristic } \\
\hline Definite IE & $252(66.3)$ & $206(66.5)$ & $46(65.7)$ & \multirow[t]{2}{*}{0.906} \\
\hline Possible IE & $128(33.7)$ & $104(33.5)$ & $24(34.3)$ & \\
\hline Complication at diagnosis & $229(60.3)$ & $173(55.8)$ & $56(80.0)$ & $<0.001$ \\
\hline Congestive heart failure & $145(38.2)$ & $111(35.8)$ & $34(48.6)$ & 0.048 \\
\hline Arrhythmia & $8(2.1)$ & $4(1.3)$ & $4(5.7)$ & 0.033 \\
\hline Neurological & $67(17.6)$ & $47(15.2)$ & $20(28.6)$ & 0.009 \\
\hline Other & $46(12.1)$ & $33(10.6)$ & $13(18.6)$ & 0.070 \\
\hline Abnormal echocardiogram ${ }^{a}$ & $324 / 372(87.1)$ & 269/308 (87.3) & $55 / 64(85.9)$ & 0.76 \\
\hline \multicolumn{5}{|l|}{ Affected valve } \\
\hline Mitral valve & $166(51.1)$ & $139(51.5)$ & $27(49.1)$ & \multirow[t]{2}{*}{0.747} \\
\hline Non-mitral valve & $159(48.9)$ & $131(48.5)$ & $28(50.9)$ & \\
\hline Vegetation observed ${ }^{b}$ & 287/372 (77.2) & 239/308 (77.6) & 48/64 (75.0) & 0.653 \\
\hline Size $\geq 1 \mathrm{~cm}$ & $118(35.6)$ & $99(36.7)$ & $19(31.1)$ & 0.16 \\
\hline Multiple vegetations & $41(12.4)$ & $14(4.5)$ & $8(13.1)$ & 0.58 \\
\hline Inappropriate empirical ABT & $57(15.1)$ & $39(12.7)$ & $18(25.7)$ & 0.007 \\
\hline Positive hemoculture ${ }^{c}$ & $311(82.3)$ & $251(81)$ & $60(87.0)$ & \multirow[t]{2}{*}{0.26} \\
\hline Streptococcus spp. & $189(60.8)$ & $167(66.5)$ & $22(36.7)$ & \\
\hline Non-streptococcus & $122(39.2)$ & $84(33.5)$ & $38(63.3)$ & \multirow[t]{2}{*}{$<0.001$} \\
\hline Staphylococcus spp. & $69(22.2)$ & $47(18.7)$ & $22(36.7)$ & \\
\hline Non-staphylococcus & $242(77.8)$ & $204(81.3)$ & $38(63.3)$ & 0.002 \\
\hline Surgical treatment & $187(49.2)$ & $168(54.2)$ & $19(27.1)$ & \multirow[t]{2}{*}{$<0.001$} \\
\hline Complication during admission & $229(60.3)$ & $159(51.3)$ & $70(100)$ & \\
\hline Neurological & $44(11.6)$ & $20(6.5)$ & $24(34.3)$ & $<0.001$ \\
\hline Congestive heart failure & $103(27.1)$ & $63(20.3)$ & $40(57.1)$ & $<0.001$ \\
\hline Arrhythmia & $60(15.8)$ & $37(11.9)$ & $23(32.9)$ & $<0.001$ \\
\hline Hospital-acquired infection & $90(23.7)$ & $51(16.5)$ & $39(55.7)$ & $<0.001$ \\
\hline Renal complication & $99(26.1)$ & $63(20.3)$ & $36(51.4)$ & $<0.001$ \\
\hline Other & $71(18.7)$ & $40(12.9)$ & $31(44.3)$ & $<0.001$ \\
\hline
\end{tabular}

A $p$-value $<0.05$ indicates statistical significance

${ }^{a}$ Available data for echocardiography 372 cases

${ }^{b}$ Available data 331 cases

${ }^{\text {c} A v a i l a b l e ~ d a t a ~} 379$ cases 
Table 3 Multivariate analysis for factors associated with overall mortality

\begin{tabular}{|c|c|c|c|c|}
\hline Factors & Crude OR $(95 \% \mathrm{Cl})$ & $p$-value & Adjusted OR $(95 \% \mathrm{Cl})$ & $p$-value \\
\hline \multicolumn{5}{|l|}{ Comorbidity } \\
\hline End-stage renal disease & $4.53(1.84-11.14)$ & 0.001 & $9.43(2.36-37.70)$ & 0.002 \\
\hline Diabetes mellitus & $3.97(2.15-7.33)$ & $<0.001$ & $2.81(1.06-7.49)$ & 0.039 \\
\hline \multicolumn{5}{|l|}{ Complication at diagnosis } \\
\hline Neurological complication & $2.24(1.22-4.096)$ & 0.009 & $2.39(0.92-6.20)$ & 0.074 \\
\hline \multicolumn{5}{|l|}{ Complication during admission } \\
\hline Neurological complication & $7.57(3.87-14.78)$ & $<0.001$ & $14.16(5.11-39.22)$ & $<0.001$ \\
\hline Congestive heart failure & $5.23(3.02-9.05)$ & $<0.001$ & $4.32(1.91-9.75)$ & $<0.001$ \\
\hline Hospital-acquired infection & $6.39(3.65-11.18)$ & $<0.001$ & $3.78(1.66-8.57)$ & 0.002 \\
\hline Renal complication & $4.15(2.41-7.15)$ & $<0.001$ & $3.12(1.32-7.37)$ & 0.009 \\
\hline Other & $5.37(3.01-9.55)$ & $<0.001$ & $3.28(1.41-7.61)$ & 0.006 \\
\hline Surgical treatment & $0.32(0.18-0.56)$ & $<0.001$ & $0.34(0.13-0.88)$ & 0.026 \\
\hline Log platelet & $0.43(0.30-0.60)$ & $<0.001$ & $0.51(0.31-0.84)$ & 0.008 \\
\hline
\end{tabular}

A $p$-value $<0.05$ indicates statistical significance

aVariable(s) entered on step 1: Age, Sex, Type of heart involvement: PVE + DRIE, Presumed mode of acquisition of IE: Healthcare associated, Comorbidity: HT, DM, Hyperlipidemia, ESRD, Inappropriate empirical antibiotic therapy, Hemoculture: non-streptococci, Complication at diagnosis: CHF, arrhythmia, neurological complication, Surgical treatment, Lab parameter: Log platelet, Cr, Complication during admit: Neurological complication, CHF, co-infection, other

${ }^{\mathrm{b}}$ Backward stepwise (Likelihood ratio) analysis

${ }^{c}$ Missing cases 72 (18.9\%)

predominant pathogen. Nevertheless, it must be noted that $25 \%$ of IE cases in one of those two studies from Thailand were found to be caused by zoonotic bacteria [6]. This supports the variability of IE etiology among countries, regions, and continents, which means that a global one-size-fits-all approach to the management of suspected IE is not appropriate. Consistent with other studies, S. aureus, CoNS, and Enterococcus spp. were the common pathogens found to cause PVE and DRIE $[1,4,16]$. In the present study, selecting ceftriaxone as an empiric antibiotic will cover up to $80 \%$ of pathogens that cause NVE.

The in-hospital mortality rate due to IE in our study was $18.4 \%$, which is high, but shows a decline from the $25 \%$ rate reported from a previous study conducted in Northeastern Thailand a decade ago [9]. However, the mortality rate in our study was slightly higher than that reported from a previous study that was conducted at our hospital over the past two decades (14\%) [8]. It must be noted that the patients in the present study were markedly older and had more comorbid disease than the patients in that previous study [8]. There also appears to be regional variability in patient mortality. Recent studies from Sweden and Finland reported 30-day mortality rates ranging from 10 to $11 \%[17,18]$. The mortality rate was higher in some developing countries [19-21], ranging from 27 to $32 \%$. The hospital mortality rate in our study was quite similar to the rates reported in a previous systematic review, which showed that the mortality rate remained stable after the 1960s at around 20\% [1]. We found the mortality rate to be higher among the
PVE or DRIE group compared to the NVE group. This could be due to the fact that the PVE or DRIE groups had more older aged patients, those patients had more comorbidities, and there was more healthcare-associated infection causing more infection with non-streptococci. This may have resulted in a higher percentage of patients receiving inappropriate empirical antibiotic therapy, which could have led to delayed treatment response, more complications, and a higher mortality rate.

ESRD, DM, and occurrence of complications during admission, including neurological complications, congestive heart failure, arrhythmia, hospital-acquired infection, or renal complication showed significant association with mortality in our study. Of interest, surgical treatment and a higher platelet level were shown to be protective factors against mortality. Our findings are somewhat similar to those from a study conducted in Turkey that found being on dialysis, having CNS emboli, and having $\mathrm{CHF}$ to be risk factors for mortality; whereas, surgical intervention and higher platelet level were the protective factors against mortality in IE patients [21]. Of note, $16 \%$ of our patients were referred and admitted to the CVT unit/ward for elective surgery. As such, most of those patients had already completed antibiotic treatments, which resulted in less severe cases and lower mortality among surgical patients. This may partly explain why surgical treatment was shown to be a protective factor for IE in our study.

This study has some limitations. First, our study's retrospective design renders it vulnerable to missing or incomplete data. For example, some baseline clinical characteristics were not recorded, particularly among 
patients transferred and admitted for surgery. In addition, we did not include only primary diagnosis of IE in this study. We have no specific data available on the number of cases that had IE as primary diagnosis. Second, the data included in this study was from a single center only. Third, our center is a national tertiary referral hospital that is commonly referred cases that cannot be effectively managed in other care settings. It is, therefore, possible that our data may not reflect IE incidence and patient characteristics at other centers. For example, a significant proportion of patients had severe disease with complication at time of diagnosis and during admission; thus, our patient population may not precisely reflect the demographic and clinical profile of patients at other hospitals. In addition, we included only I33.0 code to identify diagnosis of IE which may lead to significant bias in estimation of occurrence of IE and may not be fully comparable with previous reports that used other codes such as I38 or I39. Further prospective multicenter studies should be performed to determine the nationwide etiology and mortality of IE in Thailand.

\section{Conclusions}

The incidence of infective endocarditis is increasing in Thailand. PVE or DRIE has a higher mortality rate than NVE. Several factors, including comorbidities and complications that develop during the evolution of IE, were found to be independently associated with in-hospital mortality.

\section{Abbreviations \\ ABT: Antibiotic therapy; CA-IE: Community-acquired infective endocarditis; $\mathrm{Cl}$ : Confidence interval; CoNS: Coagulase-negative staphylococci; \\ CVT: Cardiovascular and thoracic; DM: Diabetes mellitus; DRIE: Device-related infective endocarditis; ESRD: End-stage renal disease; HACEK: Haemophilus spp., Aggregatibacter spp., Cardiobacterium spp., Eikenella spp., Kingella spp.; HA-IE: Healthcare-associated infective endocarditis; IE: Infective endocarditis; MSSA: Methicillin-sensitive Staphylococcus aureus; NIE: Nosocomial infective endocarditis; NNIE: Non-nosocomial infective endocarditis; NVE: Native valve endocarditis; OR: Odds ratio; PVE: Prosthetic valve endocarditis; SD: Standard deviation; TEE: Transesophageal echocardiography; TTE: Transthoracic echocardiography; VGS: Viridans group streptococci}

\section{Acknowledgements}

The authors gratefully acknowledge Khemajira Karaketklang and Sasima Tongsai of the Department of Medicine, Faculty of Medicine Siriraj Hospital, Mahidol University, Bangkok, Thailand for assistance with statistical analysis.

\section{Authors' contributions}

TA and NA responsible for acquisition and interpretation of data, drafting, revising the manuscript, give final approval of the version to be published.

\section{Funding}

This work was supported by a Siriraj Grant for Research Development and Medical Education, Faculty of Medicine Siriraj Hospital, Mahidol University, Bangkok, Thailand [grant no. R015931005]. The funding source had no role in the study design; in data collection, analysis, or interpretation; in the conclusions drawn; or in the preparation of the manuscript.

\section{Availability of data and materials}

The datasets used and/or analysed during the current study are available from the corresponding author on reasonable request.

\section{Ethics approval and consent to participate}

The study protocol was approved by the Scientific Ethics Committee of the Siriraj Institutional Review Board (SIRB) (COA no. 440/2558). A waiver of informed consent was approved by SIRB since the study involved no more than minimal risk to the subject and the waiver is not adversely affect the rights of the subject. The permission from Siriraj Information Technology Department (SilT) is required for secondary use of electronic health record.

\section{Consent for publication}

Not applicable.

\section{Competing interests}

All authors declare no personal or professional conflicts of interest, and no financial support from the companies that produce and/or distribute the drugs, devices, or materials described in this report.

Received: 11 August 2019 Accepted: 8 December 2019

Published online: 18 December 2019

\section{References}

1. Slipczuk L, Codolosa JN, Davila CD, Romero-Corral A, Yun J, Pressman GS, et al. Infective endocarditis epidemiology over five decades: a systematic review. PLoS One. 2013;8(12):e82665.

2. Bor DH, Woolhandler S, Nardin R, Brusch J, Himmelstein DU. Infective endocarditis in the U.S., 1998-2009: a nationwide study. PLoS One. 2013; 8(3):e60033.

3. Nakagawa T, Wada H, Sakakura K, Yamada Y, Ishida K, Ibe T, et al. Clinical features of infective endocarditis: comparison between the 1990s and 2000s. J Cardiol. 2014;63(2):145-8.

4. Vogkou CT, Vlachogiannis NI, Palaiodimos L, Kousoulis AA. The causative agents in infective endocarditis: a systematic review comprising 33,214 cases. Eur J Clin Microbiol Infect Dis. 2016;35(8):1227-45.

5. Pachirat $\mathrm{O}$, Klungboonkrong $\mathrm{V}$, Tantisirin $\mathrm{C}$, Taweesangsuksakul $\mathrm{P}$, Tasanavivat $P$, Chetchotisakd $P$, et al. Clinical outcome of native valve infective endocarditis in KhonKaen: 1990-1999. J Med Assoc Thail. 2002;85:139-46.

6. Watt G, Pachirat O, Baggett HC, Maloney SA, Lulitanond V, Raoult D, et al. Infective endocarditis in northeastern Thailand. Emerg Infect Dis. 2014;20(3): 473-6.

7. Habib G, Hoen B, Tornos P, Thuny F, Prendergast B, Vilacosta I, et al Guidelines on the prevention, diagnosis, and treatment of infective endocarditis (new version 2009): the Task Force on the Prevention, Diagnosis, and Treatment of Infective Endocarditis of the European Society of Cardiology (ESC). Endorsed by the European Society of Clinical Microbiology and Infectious Diseases (ESCMID) and the International Society of Chemotherapy (ISC) for Infection and Cancer. Eur Heart J. 2009;30(19): 2369-413.

8. Thamlikitkul V, Praditsuwan R, Permpikul C, Jootar P. Native valve infective endocarditis at Siriraj hospital, 1982-1989. J Med Assoc Thail. 1991;74:313-22.

9. Pachirat $O$, Chetchotisakd P, Klungboonkrong V, Taweesangsuksakul P, Tantisirin C, Loapiboon M. Infective endocarditis: prevalence, characteristics and mortality in KhonKaen, 1990-1999. J Med Assoc Thail. 2002;85:1-10.

10. Tleyjeh IM, Abdel-Latif A, Rahbi H, Scott CG, Bailey KR, Steckelberg JM, et al. A systematic review of population-based studies of infective endocarditis. Chest. 2007;132:1025-35.

11. Fedeli U, Schievano E, Buonfrate D, Pellizzer G, Spolaore P. Increasing incidence and mortality of infective endocarditis: a population-based study through a record-linkage system. BMC Infect Dis. 2011;11:48.

12. Sy RW, Kritharides L. Health care exposure and age in infective endocarditis: results of a contemporary population-based profile of 1536 patients in Australia. Eur Heart J. 2010;31(15):1890-7.

13. Duval X, Delahaye F, Alla F, Tattevin P, Obadia JF, Le Moing V, et al. Temporal trends in infective endocarditis in the context of prophylaxis guideline modifications: three successive population-based surveys. J Am Coll Cardiol. 2012;59(22):1968-76.

14. Tong SY, Davis JS, Eichenberger E, Holland TL, Fowler VG Jr. Staphylococcus aureus infections: epidemiology, pathophysiology, clinical manifestations, and management. Clin Microbiol Rev. 2015;28(3):603-61.

15. Hase R, Otsuka Y, Yoshida K, Hosokawa N. Profile of infective endocarditis at a tertiary-care hospital in Japan over a 14-year period: characteristics, outcome and predictors for in-hospital mortality. Int J Infect Dis. 2015;33: 62-6. 
16. Whitaker J, Williams S, Arujuna A, Rinaldi CA, Chambers J, Klein JL. Cardiac implantable electronic device-related endocarditis: A 12-year single-centre experience. Scand J Infect Dis. 2012;44:12:922-926.

17. Ahtela E, Oksi J, Porela P, Ekström T, Rautava P, Kytö V. Trends in occurrence and 30-day mortality of infective endocarditis in adults: population-based registry study in Finland. BMJ Open. 2019;9:e0268113.

18. Ternhag A, Cederström A, Törner A, Westling K. A nationwide cohort study of mortality risk and long-term prognosis in infective endocarditis in Sweden. PLoS One. 2013;8(7):e67519.

19. Al Abri SS, Zahedi FI, Kurup PJ, Al-Jardani AK, Beeching NJ. The epidemiology and outcomes of infective endocarditis in a tertiary care hospital in Oman. J Infect Public Health. 2014;7(5):400-6.

20. Arshad S, Awan S, Bokhari SS, Tariq M. Clinical predictors of mortality in hospitalized patients with infective endocarditis at a tertiary care center in Pakistan. J Pak Med Assoc. 2015:65:3-8.

21. Şimşek-Yavuz S, Şensoy A, Kaşıkçıoğlu H, Çeken S, Deniz D, Yavuz A, et al. Infective endocarditis in Turkey: aetiology, clinical features, and analysis of risk factors for mortality in 325 cases. Int J Infect Dis. 2015:106-14.

\section{Publisher's Note}

Springer Nature remains neutral with regard to jurisdictional claims in published maps and institutional affiliations.

Ready to submit your research? Choose BMC and benefit from:

- fast, convenient online submission

- thorough peer review by experienced researchers in your field

- rapid publication on acceptance

- support for research data, including large and complex data types

- gold Open Access which fosters wider collaboration and increased citations

- maximum visibility for your research: over $100 \mathrm{M}$ website views per year

At BMC, research is always in progress.

Learn more biomedcentral.com/submissions 